\title{
A SEXUALIDADE SEGUNDO MICHEL FOUCAULT: UMA CONTRIBUIÇÃO PARA A ENFERMAGEM
}

\author{
THE SEXUALITY BY MICHEL FOUCAULT: \\ A CONTRIBUTION TO NURSING
}

Moneda Oliveira Ribeiro*

RIBEIRO, M.O. A sexualidade segundo Michel Foucault: uma contribuição para a enfermagem. Rev.Esc.Enf.USP., v. 33 , n. 4 , p. 358-63, dez. 1999 .

\begin{abstract}
A autora desenvolve uma reflexão sobre a concepção de Foucault em relação ao "dispositivo da sexualidade" apresentada no livro "Microfísica do Poder". Busca resgatar, através dessa literatura clássica, uma visâo histórico-social da prática de enfermagem, tendo em vista a racionalidade atual que deprecia a afetividade nas relações pessoais ao supervalorizar a virilidade masculina, tornando o prazer um bem de consumo e um fim em si mesmo.
\end{abstract}

UNITERMOS: Sexualidade.

The author develops a reflexion about Foucault conception in relation to the "sexuality dispositive" that has been presented in the book "Microfisica do Poder". She tries to rescue, through this classic literature, a historic and social point of view in the practice of nursing, without missing the actual concepts that depreciate the affection of the personal relations at overvalorize the masculine virilate, converting the pleasure a consumer goods and a goal itself.

UNITERMS: Sexuality.

\section{INTRODUÇÃO}

A profissão de enfermagem, ao introjetar a racionalidade científica da Ética Protestante a partir do século XIX, passou a encarar a sexualidade como uma questão essencialmente biológica, a-política, a-histórica e universal. A partir dessa nova racionalidade, questões de caráter psico-social foram dissociadas de sua prática. O extremo rigor na classificação das distintas disciplinas científicas ${ }^{3}$, excluiu da enfermagem qualquer relação com as atividades de âmbito psico-social. Passava a ser de competência desta profissão somente o cuidado físico do paciente. Os aspectos psíquicos competiam exclusivamente ao psicólogo, e os aspectos sociais competiam ao assistente-social. A enfermagem deixou de participar do conjunto global, integrado e dinâmico de seu paciente/cliente. O resultado foi a compartimentalização do paciente em partes isoladas e desarticuladas.
A nova racionalidade surgida na Modernidade, levou ao esquadrinhamento das profissões liberais ${ }^{4} \mathrm{e}$, devido ao seu caráter universal, atingiu todas instâncias político-sociais da sociedade ocidental. Neste contexto, a abordagem da sexualidade não dizia respeito à enfermagem, somente à psicologia, sobretudo à psicanálise. Mas o profissional enfermeiro nunca deixou de deparar-se com situações de natureza sexual ao prestar cuidados ao paciente, principalmente a partir do século XIX, quando a sexualidade passou a constituir um problema; ou seja, passou a ter uma conotação pejorativa, a ser vista como um ócio, um ato imoral quando praticado sem fins reprodutivos.

Justamente por constituir um problema, surgia a necessidade dos profissionais refletirem sobre essa temática. Mas, paradoxalmente, foi justamente nessa época em que mais se proibia qualquer análise que

\footnotetext{
- Enfermeira. Professor Doutor do Departamento de Enfermagem Materno-Infantil e Psiquiátrica da Escola de Enfermagem da USP (e-mail moneda @ usp.br)
} 
conduzisse à denúncia da relação existente entre a repressão sexual e as relações de poder. A repressão sexual passava a ser necessária para viabilizar 0 exercício do poder conforme as condições da nascente ordem social burguesa.

Não é por acaso que a abordagem da sexualidade humana nas escolas secundárias e nas universidades ainda é um tópico pouco debatido. As escolas de enfermagem não fogem à regra. Não existe orientação, de modo estrutural e sistemática, em relação à abordagem do paciente quanto às questões de natureza sexual na formação do enfermeiro. A discussão sobre 0 tema durante a formação desse profissional aparece isolada e casualmente nos programas do curso de graduação. Nestes casos, o tema é debatido por iniciativas individuais ou de um grupo.

Contudo, nos trabalhos apresentados em eventos científicos e nas publicações de algumas editoras, verifica-se que os profissionais de enfermagem, no Brasil, têm demonstrado preocupação crescente em repensar sua prática à luz de uma perspectiva histórica. Questões como ideologia, poder e hegemonia têm sido analisadas e discutidas com o fim de caracterizar a profissão num contexto político-sócio-cultural.

Assim, com este trabalho espera-se contribuir para o incremento do propósito de repensar a prática da enfermagem no que diz respeito à questão da sexualidade. Objetiva-se, no momento, apenas apresentar uma análise crítica da concepção de "dispositivo da sexualidade" segundo a visão de FOUCAULT ${ }^{2}$, com o fim de proporcionar reflexões sobre os complexos mecanismos que geraram o desconforto sentido nas interações pessoais que envolvem questões de natureza sexual.

Para tanto, estão sendo considerados nessa análise os capítulos "Não ao rei" $\mathrm{e}$ "Sobre a história da sexualidade" da bibliografia "Microfísica do poder"de sua autoria, por ser esta a referência onde ele esclarece seu pensamento, de forma clara, objetiva e concisa, em relação ao que chamou de "dispositivo da sexualidade".*

\section{O DISPOSITIVO DA SEXUALIDADE}

Foucault é visto como o historiador das proibições e do poder repressivo porque buscava o discurso das "verdades" produzidas e analisava como o poder, que se exerce sobre a loucura e a sexualidade, produziu o discurso "verdadeiro" da psiquiatria e da sexologia, respectivamente. FOUCAULT ${ }^{2}$ afirmava que nas sociedades ocidentais, durante séculos, se ligou o sexo à busca da verdade, sobretudo a partir do cristianismo. A confissão, o exame da consciência, foi o modo de colocar a sexualidade no centro da existência. $O$ sexo, nas sociedades cristãs, tornou-se algo que era preciso examinar, vigiar, confessar e transformar em discurso. Podia-se falar de sexualidade, mas somente para proibi-la. O esclarecimento, a "iluminação" da sexualidade se deu nos discursos e na realidade das instituições e das práticas. As proibições faziam parte de uma economia complexa.

$O$ autor, em seus estudos, não se propôs a fazer a sociologia histórica da proibição, mas a história política de uma produção de "verdades". Dizia que vivemos em uma sociedade que produz discursos tidos como verdades. Essa produção de "discursos verdadeiros" resulta na formação de poderes específicos. Assim, sustenta que as "verdades" produzidas em relação a sexualidade tornou-se um problema no Ocidente, uma vez que levaram à repressão sexual.

Apesar da explicitação discursiva, o autor reconhecia que a repressão e a miséria sexual existem. Mas ele não se preocupava em explorar a natureza da ideologia vigente $e$ suas conseqüências em relação à sexualidade. Não se propôs a analisar as formas e as condições desta repressão e miséria, mas se preocupava em fixar o "método" que as engendram. Para ele, o capitalismo não tem o propósito de privar a sexualidade, mas não pode desenvolver-se sem privá-la. Seu enfoque consiste em apreender os mecanismos positivos que, ao produzir a sexualidade de determinada maneira, acarretam efeitos repressivos e de miséria. Cita, como exemplo, a exagerada importância dada à masturbação infantil a partir do século XVIII, perseguida como uma epidemia terrível.

$\mathrm{Na}$ época, visava-se a reorganização das relações entre o mundo adulto e a criança; sendo esta vista apenas como a semente de futuras gerações. O sexo da criança tornava-se alvo e instrumento de poder. Daí uma miséria sexual da infância e da adolescência de que nossas gerações ainda não se livraram; mas o objetivo procurado não era esta miséria, não era proibir. O fim era constituir, através da sexualidade infantil, (...) uma rede de poder sobre a infância.

A idéia de que a miséria sexual provém da repressão (que é também efeito do mesmo dispositivo que gerou a própria miséria) e que, para ser feliz, temos que liberar nossa sexualidade, advém dos sexólogos, dos médicos ou de outros detentores do saber, diz o autor. Estes apresentam a revelação (a eles) dos segredos que oprimem o indivíduo como solução das frustrações sexuais em busca da libertação. Tal discurso é, segundo FOUCAULT ${ }^{2}$, um instrumento de controle e de poder, pois sustenta a idéia de que é suficiente, para ser feliz, ultrapassar o umbral do discurso e eliminar algumas proibições. Considera, então, que esse discurso acaba por depreciar e esquadrinhar os movimentos de revolta e libertação.

\footnotetext{
- Para maior aprofundamento de sua teoria, sugere-se a leitura de seus três livros classicos: FOUCAULT, M. História da sexualidade. $11 \mathrm{ed}$. Rio de Janeiro, 6 raal, 1993. v. 1-3
} 
Tal pressuposto levou à compreensão (errônea, segundo o autor) de que não há diferença entre repressão e liberação do sexo, nem entre o discurso da censura e o da contra-censura. Ele alega que os movimentos ditos de "liberação sexual" são movimentos de afirmação que partem do dispositivo da sexualidade (que nos aprisiona); são movimentos que fazem com que o dispositivo funcione até seu limite mas que, em contrapartida, se livram dele e o ultrapassam. Não especifica, entretanto, que limite é este, nem detalha como os movimentos de libertação se livram e ultrapassam o dispositivo da sexualidade que oprimiu o sexo. Mas, é nesta perspectiva que apresenta a superação da repressão e da miséria sexual.

$O$ autor enfoca a questão da homossexualidade, ponderando que, em torno de 1870 , os psiquiatras passaram a considerá-la como objeto de análise médica, ponto de partida para a introjeção de novas intervenções e controles. Os homossexuais passaram, assim, a ser percebidos como loucos ou doentes do instinto sexual. Antes, eram considerados libertinos ou delinqüentes. Surge, então, a invenção estratégica da "mesma" vontade de verdade. $O$ mesmo acontece com as demais minorias: a mulher, o negro, etc. Os mesmos mecanismos levam à patologização da mulher ao considerar seu sexo frágil, quase doente. Os movimentos feministas aceitam o desafio ao assumirem sua singularidade e suas conseqüências, e reinventam seu próprio tipo de existência partindo dessa sexualidade que as aprisionam para direcionarem-se à outras afirmações, conclui o autor.

Nesta perspectiva, FOUCAULT ${ }^{2}$ está considerando que um mesmo dispositivo produz fenômenos semelhantes. Ou seja, a estratégia que produziu a "patologização" do homossexual, produziu também a da mulher, da criança e de outras minorias. Não é seu propósito distingüir e questionar as diferentes correntes dos movimentos de libertação. Parece considerá-los como uma forma homogênea, embrionária, que tomarão corpo somente quando se constituírem como discurso e estiverem em posição de exercer o poder. Nesta visão, parte do pressuposto de que o mecanismo que origina a opressão é o mesmo que gera a libertação. Em outras palavras, os agentes sociais partem sempre do mesmo dispositivo ou estratégia para inovarem um discurso e o exercício do poder. Este poderá ser opressor sobre uma minoria ou, ao contrário, libertador da mesma.

$O$ autor refere, por exemplo, que o importante nos movimentos de libertação da mulher não é a reivindicação em si, mas o fato de terem partido do próprio discurso que era formulado no interior dos dispositivos de sexualidade. Os movimentos surgem no século XIX como uma verdadeira "dessexualização", como um deslocamento em relação à centralização sexual do problema, para reivindicar formas de cultura, de discurso, de linguagem, e outros, diferente da determinação e fixação vigente.
FOUCAULT ${ }^{2}$ relata que, atualmente, está se esboçando um movimento contra esta "sexografia" que decifra o sexo como segredo universal. Trata-se de fabricar outras formas de prazer, de relações, de coexistências, de laços de amores. Em relação às crianças, começa a se esboçar um discurso em que a vida da criança consiste basicamente em sexualidade. Por isso questiona se tal discurso é libertador, se não aprisiona as crianças em um tipo de insalubridade sexual; se a liberdade de não ser adulto consiste justamente em não estar dependente de uma lei ou princípio, tão entediante, da sexualidade; e se não seriam as relações polimorfas (ou seja, as relações sem padrões de comportamento) a própria infância, caso isso fosse possível. Mas considera que o polimorfismo, ao contrário, é visto pelos adultos (por questão de segurança) como perversidade. Desta forma, a criança passa a ser oprimida inclusive por aqueles que pretendem libertá-la.

Para ele, o dispositivo da sexualidade já existia antes da Modernidade. Parte do princípio de que a civilização implica regras sociais sem as quais se instala a barbárie, e a "regulamentação sexual" é essencial à organização da sociedade. Contudo, se esse dispositivo já se manifestava antes dessa Era, como ele explica, o que tornou o discurso tão evidente a partir dessa época? A "regulamentação sexual" teria sido levada ao extremo a ponto de se substituir o termo "regulamentação" por "repressão" sexual? O que determinou que, antes da Era Moderna, a sexualidade era "regulamentada" e, a partir dela, tornou-se "repressiva"?

Segundo FOUCAULT ${ }^{2}$, a sexualidade é um comutador que nenhum sistema moderno de poder pode dispensar. Ela não é aquilo que o poder tem medo, mas aquilo que se usa para seu exercício. As proibições não são formas essenciais do poder, são apenas seus limites, as formas frustradas. As relações de poder são, antes de tudo, produtivas. $\mathrm{O}$ foco principal do autor são os efeitos do poder e a produção de "verdade". Para ele, a noção de "ideologia" foi utilizada para explicar erros em tudo que impede a formação de discursos verdadeiros e para mostrar a relação entre o pensamento e as relações de produção; foi a economia do nãoverdadeiro. $\mathrm{O}$ autor, longe disso, preocupou-se em investigar o que está oculto nas relações de poder, inclusive nas infra-estruturas econômicas e não apenas nas estruturas estatais. Para ele, $a$ partir do momento em que há uma relação de poder, há uma possibilidade de resistência. Há sempre a possibilidade de modificar uma dominação sob determinadas condições e conforme uma estratégia adequada.

É nesse sentido que expõe como se dão as mudanças sociais. Explica que o poder é um feixe de relações organizado, piramidalizado e coordenado, mas que sempre há movimentos que levam as estratégias (que coordenam as relações de poder) a produzirem 
efeitos novos e domínios que, até determinado momento, não eram previstos. $\mathrm{O}$ autor, então, diverge do enfoque apresentado pelos marxistas quanto às mudanças sociais, pois estas ocorrem independente da "luta de classes". Segundo ele, os marxistas não expõem concretamente o que é essa "luta", somente a menciona como força motriz da história; detêm-se apenas em explicar o que é a classe, onde se situa e quem a engloba. Apesar disso, refere não ter a pretensão de preencher esta lacuna.

\section{DISPOSITIVO: uma estratégia de produção de discursos e poder}

FOUCAULT ${ }^{2}$ emprega o termo "dispositivo" quando refere-se aos discursos que consistem em: um programa de uma instituição, ou uma justificativa de uma prática (ou sua reinterpretação) e/ou uma nova racionalidade. Emprega o termo, também, para referirse às instituições, às organizações arquitetônicas, às decisões regulamentares, às leis, às medidas administrativas, aos enunciados científicos e às proposições filosóficas, morais e filantrópicas. Enfim, define o dispositivo como um conjunto heterogêneo, ou melhor, como uma estrutura de elementos heterogêneos. Segundo ele, o dispositivo consiste na natureza da relação entre os elementos constituintes desse conjunto heterogêneo. Trata-se de uma formação que, em determinado momento histórico, responde a uma urgência. Portanto, para ele, o dispositivo é uma espécie de gênese.

O dispositivo, segundo o autor, abrange um "objetivo estratégico" que produz dois efeitos: um, voluntário, que estabelece uma relação de ressonância ou de contradição entre seus elementos (através de uma rearticulação, um reajustamento dos elementos heterogêneos dispersos); e outro, involuntário e negativo, que não era previsto na estratégia produzida, mas que passa a ser um efeito que ocupa um vazio ao se transformar o negativo em positivo (como ocorreu com a prostituição, um efeito negativo, imprevisto, que tornou-se positivo ao se extrair dele o lucro do prazer).

FOUCAULT ${ }^{2}$, ao excluir a idéia de sujeito, não relaciona o fato a um agente, ou seja, não evidencia o fato de que a utilização do efeito imprevisto, por exemplo, tornou-se positivo para quem detém o poder. Há implícito neste panorama, sujeitos ou agentes (sejam estes oportunistas, elementos do aparelho do Estado, um grupo empresarial, banqueiros, políticos partidários, expeculadores, entre outros) que controlam a máquina administrativa de re-utilização dos "efeitos imprevistos" em favor de seus próprios interesses. Este "complexo heterogêneo", em seu conjunto, constitui um "todo homogêneo dominante" que passa a compor uma categoria, uma entidade, ou uma classe social. Portanto, está aí expresso o sujeito "vencedor" desse jogo de poder que envolve relações estratégicas de forças.

O autor refere que o "dispositivo" é de natureza essencialmente estratégica, está sempre inscrito em um jogo de poder e ligado às configurações do saber. Trata-se de uma manipulação, de uma intervenção racional e organizada das relações de força. $O$ dispositivo da sexualidade implica a "epistéme" e a "instituição". A primeira é um dispositivo estratégico, somente discursivo, que permite escolher o enunciado mais aceitável dentre os possíveis de um campo de cientificidade. A epistéme permite separar 0 inqualificável cientificamente do qualificável, o falso do verdadeiro. A segunda envolve todo comportamento coercitivo e aprendido, consiste em tudo que funciona como sistema de coerção sem ser um enunciado, é toda ação social não discursiva.

\section{DISPOSITIVO: uma estratégia sem sujeito}

FOUCAULT ${ }^{2}$ apresenta o dispositivo como uma estratégia sem sujeito. Trata-se, segundo ele, de uma rede de instituições e de mecanismos de apoio (podendo ser, por exemplo, sindicatos, associações, categorias) que inventam, modificam, reajustam, segundo as circunstâncias do momento e do lugar, a ponto de se obter uma estratégia global, coerente, racional. Mas defende que não é possível dizer quem concebeu a estratégia. Para ele, uma classe dominante não é uma abstração, mas também não é um dado prévio, é efeito de táticas sistemáticas efetivas das grandes estratégias que fixam e reproduzem a dominação.

Ele admite que a estratégia de moralização da classe operária é a da burguesia, e é a que lhe possibilita constituir-se como classe burguesa dominante, mas ressalva que não foi a classe burguesa, enquanto sujeito, que inventou e impôs (através de sua ideologia) esta estratégia à classe operária. Refere que a moralização desta classe realizou-se em resposta a um objetivo (o de dominar uma mão-de-obra ociosa) que acabou por se impor. Assim conclui que, ao exigir um objetivo, a estratégia desenvolveu-se.

Entretanto, o autor não leva em conta que a classe burguesa pode não constituir um dado prévio, mas originou-se a partir da união de grupos que tinham interesses comuns; tornando, dessa forma, possível identificá-la na sua forma embrionária como o agente produtor da ordem moral que manteria o statu-quo. Não parece inviável identificar o sujeito que, embora seja fruto das grandes estratégias, foi também quem concebeu a estratégia que produziu a dominação.

FOUCAULT ${ }^{2}$ justifica seu argumento usando como exemplo a "constituição de um dispositivo médicolegal" que insere a psiquiatria no domínio penal e aumenta os controles e as intervenções penais sobre a conduta dos cidadãos. Assim, médicos e magistrados passaram a intervir nesse terreno penal. 
Em relação aos médicos, diz ele, havia uma "necessidade" (que não consistia necessariamente em interesse, refere o autor) de reconhecer a psiquiatria como parte da higiene pública, cuja intervenção se fundaria não só na doença a ser tratada como também no combate ao perigo. A loucura era apresentada como perigo, na medida em que podia tornar-se um crime. Neste caso, só o médico tinha competência para "prever" o perigo. A loucura, então, tornou-se objeto exclusivo da psiquiatria, atribuindo-se ao médico o direito à intervenção.

Em relação aos magistrados, sustenta que uma outra "necessidade" os levou a aceitar a intervenção dos médicos. Os magistrados, através da prisão, buscavam intervir sobre o criminoso (e não sobre o crime) a fim de transformá-lo. A loucura perigosa era a que produzia "crime sem criminoso", pois tratava-se de um crime sem motivo para tal e, por isso, o indivíduo não podia ser punido. Nesse sentido, os magistrados lançaram mão da psiquiatria para atender essa especificidade. Temos então (segundo ele) necessidades estratégicas que não são exatamente interesses.

$\mathrm{O}$ autor não detalha, entretanto, a distinção que faz entre "necessidade" e "interesse". Ao substituir o segundo pelo primeiro, não explicita a intencionalidade dos sujeitos constituintes no que chamou de "dispositivo médico-legal". Em uma rede de relações de forças, há sempre os que têm necessidades a serem atendidas e os que têm interesses a defender. Além dos médicos e dos magistrados, havia o pessoal administrativo, diz ele. Mas, participaram dessa estratégia, provavelmente, outros elementos ou grupos da sociedade civil. Sendo assim, será que o surgimento do dispositivo médico-legal não ultrapassou o âmbito da necessidade? Os médicos e os magistrados que tinham necessidades (e não interesses) de reconhecer a psiquiatria como parte da higiene pública não seriam constituintes dos chamados "mecanismos de apoio"? Mecanismos estes que, por razões distintas, participaram da produção de afirmações que atenderam as necessidades de um grupo, mas que também defenderam (ainda que involuntariamente) os interesses de grupos dominantes?

FOUCAULT ${ }^{2}$ refere que é necessário haver uma "manobra" para que determinada relação de força possa instituir-se, estabilizar-se e avançar. Assim, considera que a psiquiatria manobrou para conseguir ser reconhecida como parte da higiene pública. $\mathrm{O}$ autor, ao mencionar a "psiquiatria" parece referir-se a um corpo homogêneo. No entanto, segundo sua descrição, é próprio de qualquer dispositivo constituir-se num conjunto heterogêno. Contudo, o autor não aponta quais são os elementos constituintes desse conjunto, não identifica seus agentes. Ele a apresenta como um dispositivo, ou seja, um agente ativo que produz novas racionalidades, mas não aponta quais são os elementos que constituem o conjunto heterogêneo, próprio de qualquer dispositivo, segundo sua descrição.
Nesse enfoque, não é de se estranhar que seja inviável a identificação de grupos que se mobilizam para atender uma necessidade e grupos que se articulam para atender seus interesses. Se se resgata os fatos históricos, os trâmites e acordos que regulamentaram o reconhecimento da psiquiatria como parte da higiene pública e toda dinâmica que envolveu esse processo, seria possível identificar sujeitos dessa estratégia.

A identificação do sujeito, em sua análise, pode ser uma questão secundária, insignificante para seu propósito, mas a idéia de "estratégia sem sujeito" não convence. Sua análise elimina a idêia de um sujeito pensante e atuante. Elimina, conseqüentemente, a intencionalidade desse sujeito e sua posição no conjunto de uma sociedade onde as relações são de dominação. Além disso, a idéia de inexistência de um sujeito enfraquece a ação militante. Numa relação de força entre dominante e dominado, é fundamental identificar qual é o inimigo que resiste à conquista de uma reivindicação para o atendimento de uma necessidade; sem o qual, o movimento de libertação torna-se disperso. Nesses movimentos, há confrontos entre grupos dominantes (que oprimem) e grupos dominados (que sofrem essa opressão). Os primeiros podem não constituir a classe dominante por si só, mas são integrantes dela.

A construção de uma nova afirmação libertadora que parte da própria afirmação opressora anterior, depara-se com um sujeito que tem interesses próprios e específicos a defender, mas que também são condizentes com os da classe a qual pertence. Está aí, um campo prático de luta onde, através de interesses e necessidades específicas, configura-se um confronto com objetivos estratégicos específicos, mas que refletem conflitos de âmbito maior, ou seja, o de classe social.

Numa perspectiva marxista, os movimentos de libertação das minorias apresentam objetivos específicos, mas refletem uma contradição que os marxistas a caracterizam como "não-antagônica". Tal contradição compreende uma extensão da contradição "antagônica" que consiste na luta de classes. Esta, então, não se manifesta apenas no momento de revolução; manifestase também através desses confrontos específicos que não aspiram tomar o poder propriamente dito, mas buscam conquistas específicas que permitem avançar na superação dos conflitos decorrentes de uma estrutura social dividida em classes.

FOUCAULT ${ }^{2}$ é contundente ao afirmar que a questão da luta de classes é pouco aprofundada pelos marxistas, uma vez que estes (salvo talvez em Trotsky, segundo ele) silenciam sobre o que se entende por "luta", sobretudo por "luta de classes". A questão básica consiste em especificar como a luta de classes se expressa no processo revolucionário, ou seja, como ela se manifesta até a almejada tomada do poder pela classe proletária. Entretanto, o autor parte para outro extremo ao afirmar que "nós lutamos todos contra todos" e 
que "não há, dados de forma imediata, sujeitos que seriam o proletariado e a burguesia". Essa resistência do autor em identificar os sujeitos obnubila, evidentemente, os interesses de classes presentes nos dispositivos que geram novas afirmações.

Para explicar a ausência de sujeito na estratégia, o autor menciona que a monarquia absoluta francesa na realidade não tinha nada de absoluto, pois seu poder era disseminado, descentralizado e não se exprimia em grandes estratégias. No século XIX, por outro lado, o poder burguês pôde elaborar grandes estratégias, sem que por esse motivo se precise supor um sujeito. Com esta afirmação, ele dá a entender que o "poder real" francês consistia em um sujeito sem estratégia e o "poder burguês" em uma estratégia sem sujeito. Partindo dessa visão, pode-se concluir que o autor só admite a existência de um sujeito se expresso na forma de uma figura representativa, de um corpo bem delimitado. Mas o sujeito ou agente de uma estratégia pode ser um grupo, uma categoria, uma classe, uma entidade, etc., que têm necessidades, interesses e objetivos bem definidos.

\section{CONCLUSÃO}

FOUCAULT ${ }^{2}$, enfim, faz do sexo um objeto histórico gerado pelo dispositivo da sexualidade. Preocupou-se, como ele mesmo diz, em analisar o que aconteceu no Ocidente que faz com que a questão da verdade tenha sido colocada em relação ao prazer sexual. Preocupou-se, sobretudo, em abordar a sexualidade no âmbito do discurso científico. Esse enfoque foi o grande mérito do autor, pois aborda a sexualidade em um prisma nunca pensado até o momento.

É preciso olhar para trás, rever o passado, para compreender o presente e prever o futuro. $O$ comportamento social da sexualidade atual, ou seja, a forma como a sexualidade está regulamentada deixa dúvidas se não vivemos noutra forma de opressão, na qual se deve desfrutar do prazer pelo prazer, sendo este um fim em si mesmo.

Qual é a nova racionalidade que conduz o homem atual a praticar a sexualidade com vistas somente ao prazer e a valorizar tanto a virilidade masculina e seu desempenho sexual? Que racionalidade é essa em que a união entre os casais se dá por atração física apenas, negligenciando a afetividade ao deixá-la em plano secundário. Chamaremos isso de liberação sexual? É liberação praticar a sexualidade de forma desorientada, seguindo o modismo, sem considerar a afeição?

Que liberação é esta que abrevia o processo de desenvolvimento humano do elevado número de adolescentes que engravidam sem antes estarem aptas para assumir os encargos de um adulto? Que liberação é esta que ainda é complacente com a omissão masculina em relação ao compromisso com a paternidade e as tarefas domésticas?

A sexualidade, hoje, sofre influência do dispositivo que concebeu uma sociedade voltada para o consumo e, como tal, é efeito desse dispositivo. A sexualidade humana só será livre quando regulamentada em função do atendimento das próprias necessidades humana e não como conseqüência de estratégias que objetivam o exercício do poder.

O profissional enfermeiro precisa refletir sobre os mecanismos que geram valores e atitudes em relação à sexualidade para, ao invés de basear-se cegamente no padrão vigente, construir uma "verdade" pautada em seus próprios sentimentos e, dessa forma, caminhar para uma prática coerente com suas necessidades e não conforme os interesses decorrentes das relações de poder.

\section{REFERÊNCIA BIBLIOGRÁFICA}

1. FOUCAULT, M. Microfísica do poder. 4. ed. Rio de Janeiro, Graal, 1984. cap. 15, p. 229-42: não ao sexo rei.

2. FOUCAULT, M. Microfísica do poder. 4. ed. Rio de Janeiro, Graal, 1984. cap. 16 , p. 243-76: sobre as história da sexualidade.

3. FOUCAULT, M. As palavras e as coisas. 6. ed. São Paulo, Martins Fontes, 1992. cap. 5, p. 139-78: Classificar

4. FOUCAULT, M. As palavras e as coisas. 6. ed. São Paulo, Martins Fontes, 1992. cap. 10, p. 361-404: As ciências humanas. 